13.1;06.1

\title{
$N$-образные вольт-амперные характеристики гибридных органических материалов на основе цинковых комплексов
}

\author{
(C) А.Н. Гусев, А.С. Мазинов , В.С. Гурченко, А.С. Тютюник, Е.В. Брага \\ Крымский федеральный университет им. В.И. Вернадского, Симферополь, Россия \\ ฯ E-mail: mazinovas@cfuv.ru
}

Поступило в Редакцию 16 ноября 2020г.

В окончательной редакции 30 декабря 2020 г.

Принято к публикации 31 декабря 2020г.

Исследованы вольт-амперные характеристики гибридных органических материалов $\mathrm{C}_{48} \mathrm{H}_{42} \mathrm{~N}_{6} \mathrm{O}_{2} \mathrm{Zn}$ и $\mathrm{C}_{54} \mathrm{H}_{54} \mathrm{~N}_{6} \mathrm{O}_{2} \mathrm{Zn}$. Описаны методика получения, микроскопия, а также результаты инфракрасной спектроскопии и исследования электрических свойств полученных тонких пленок данных органических материалов на основе цинковых комплексов. Представлены результаты расчета оптической ширины запрещенной зоны. Установлено, что полученные тонкопленочные структуры обладают $N$-образными вольт-амперными характеристиками.

Ключевые слова: $N$-образные вольт-амперные характеристики, цинковый комплекс, тонкопленочные структуры, оптическая ширина запрещенной зоны.

DOI: 10.21883/PJTF.2021.08.50843.18617

Устройства, обладающие отрицательным дифференциальным сопротивлением (NDR), в последнее время стали привлекать большое внимание исследователей и разработчиков [1]. Полупроводниковые структуры со свойствами NDR имеют огромный потенциал применения в генераторах, логических устройствах и элементах памяти [2,3]. Обычно для разработки таких устройств используют полимеры с сопряженными связями (синтетические металлы) [4], гибридные неорганические перовскиты [5] или гетероструктуры на основе оксидов металлов [6]. Однако воздействие различных видов излучения, температуры и других внешних факторов по-прежнему существенно влияет на стабильность эффекта NDR [7].

Использование органических материалов, которые обладают отрицательным дифференциальным сопротивлением, набирает все бо́льшую популярность по сравнению с применением неорганических материалов ввиду гибкости молекулярной модификации и простоты нанесения [8]. Кристаллические органические гибридные материалы на основе цинковых комплексов, состоящих из неорганических и органических фрагментов или модулей, не только обладают интересными структурными особенностями, но и проявляют интересные свойства как новые функциональные материалы, которые могут быть использованы в областях люминесценции, адсорбции и катализа, а также в качестве сенсоров и т. д. $[9,10]$.

В настоящей работе предпринята попытка рассмотрения цинковых комплексов с азометинами 4-бензоилпиразолона в качестве активных устройств, обладающих отрицательным дифференциальным сопротивлением.

Синтез цинковых комплексов осуществлялся по следующей методике. Суспензию $2 \mathrm{mmol}$ соответствующих лигандов и $219 \mathrm{mg}(1 \mathrm{mmol}) \mathrm{Zn}(\mathrm{AcO})_{2} \cdot 2 \mathrm{H}_{2} \mathrm{O}$ в $50 \mathrm{ml}$ безводного метанола кипятили при перемешивании в течение 4 h. Образовавшийся осадок отделяли фильтрованием, промывали холодным метанолом и сушили в вакууме. На выходе были получены вещества светложелтого цвета: $\mathrm{ZnL}_{2}\left(\mathrm{C}_{48} \mathrm{H}_{42} \mathrm{~N}_{6} \mathrm{O}_{2} \mathrm{Zn}\right)$, выход 85\%, и $\mathrm{ZnL}_{2}\left(\mathrm{C}_{54} \mathrm{H}_{54} \mathrm{~N}_{6} \mathrm{O}_{2} \mathrm{Zn}\right)$, выход 85\%. В качестве лигандов использовались азометиновые производные 4-бензоил5-метил-2-фенил-2,4-дигидро-3-Н-пиразол-3-она, где для соединения $\mathrm{ZnL1}_{2}$ свободным радикалом служил $\mathrm{H}$, а для $\mathrm{ZnL}_{2}-\left(\mathrm{CH}_{3}\right)_{3} \mathrm{C}$.

Формирование пленочных структур осуществлялось методом полива из соответствующих растворов, изготовленных из исходных твердотельных соединений цинковых комплексов (Zn-complex). В качестве растворителя был использован хлороформ $\left(\mathrm{CHCl}_{3}\right)$, концентрация исходного вещества в растворе составила $2 \mathrm{mg} / \mathrm{ml}$. Для исследования воздействия электромагнитных волн оптического и инфракрасного (ИК) диапазонов на пленки цинкового комплекса подготовленные растворы были нанесены на стеклянные подложки при объеме последних $1 \mathrm{ml}$. Для исследования электрических параметров цинковые соединения того же объема наносились на проводящие подложки - оксид индия-олова (ITO) и алюминий, полученные методом вакуумного напыления, с последующим формированием сандвич-структуры ITO-Zn-complex-Al. Удельное сопротивление ITO составляло 16-18 $\Omega / \mathrm{sq}$, сопротивление алюминия $20 \Omega /$ sq. Геометрические параметры стеклянных и проводящих подложек составляли $10 \times 10 \mathrm{~mm}$.

Геометрия поверхности играет важную роль при взаимодействии электромагнитных волн оптического и средневолнового ИК-диапазона с исследуемыми тонкими пленками цинковых комплексов, а также при исследовании их проводящих свойств. В связи с этим морфология поверхности пленочных структур (орга- 

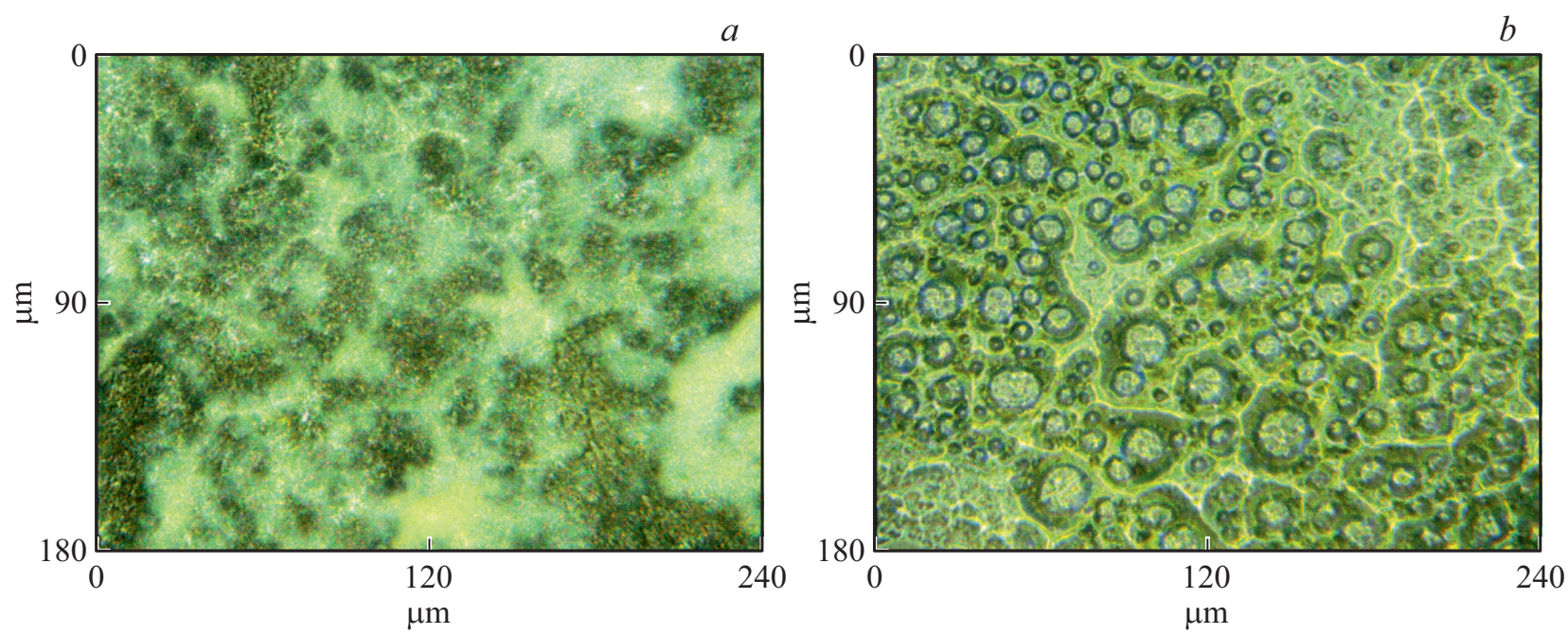

Рис. 1. Микрометрия органических пленок $\mathrm{ZnL}_{2}(a)$ и $\mathrm{ZnL}_{2}(b)$.
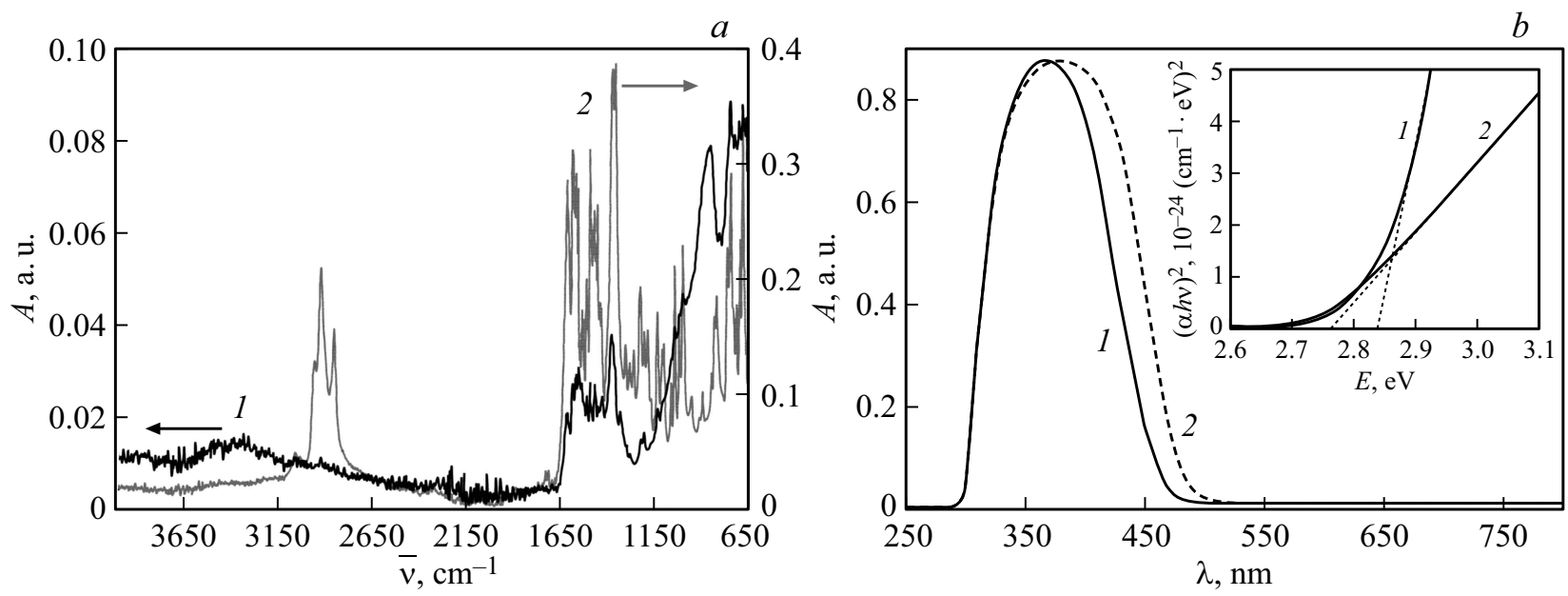

Рис. 2. ИК-спектры $(a)$ и оптические спектры $(b)$ поглощения органических соединений $\mathrm{ZnL1} 1_{2}(1)$ и $\mathrm{ZnL} 5_{2}(2)$.

нических соединений $\mathrm{ZnL5}_{2}$ и $\left.\mathrm{ZnL1}_{2}\right)$ контролировалась посредством отражающей и просвечивающей микроскопии на микроинтерферометре ЛОМО Мии-4М. Исследования взаимодействия волн ИК-диапазона с цинковыми комплексами проводились на ИК-Фурьеспектрометре Agilent Cary 630 в диапазоне волновых чисел $650-4000 \mathrm{~cm}^{-1}$ с разрешением $4 \mathrm{~cm}^{-1}$. Для регистрации спектров поглощения в видимом диапазоне применялся спектрофотометр GBC Cintra 4040. Использование в качестве источников вольфрамовой и дейтериевой ламп позволило реализовать диапазон падающего излучения от 250 до $800 \mathrm{~nm}$ с шириной щели $0.1-2 \mathrm{~nm}$. Проводящие свойства в режиме постоянного тока исследовались при помощи анализатора полупроводников Keysight B1500A.

Предварительный анализ морфологии поверхности пленочных структур цинковых органических соединений $\mathrm{ZnL1}_{2}$ и $\mathrm{ZnL} 5_{2}$ показал ее относительную однородность. Толщина пленки $\mathrm{ZnL1}_{2}$ в среднем составляет $1.1 \mu \mathrm{m}$, тогда как минимальная толщина имеет величину порядка $0.8 \mu \mathrm{m}$ (рис. 1, $a$ ). Модификация цинкового комплекca $\mathrm{ZnL5} 2$ характеризуется толщинами пленки порядка $3.5 \mu \mathrm{m}$, однако данный материал отличается наличием отдельно выраженных микроструктур сферической формы. Диаметр данных образований варьируется в диапазоне от 2.6 до $24 \mu \mathrm{m}$ (рис. $1, b$ ).

Последовательный анализ ИК-спектров поглощения пленок цинковых комплексов показал наличие пиков, характерных для колебаний функциональных групп органических лигандов. Наиболее интенсивные полосы ИК-спектра соединения $\mathrm{ZnL}_{2}$ на $\mathrm{KBr}$-оптике совпадают с полосами в ИК-спектре порошка этого же соединения и расположены при 1590, 1573, 1546, 1483, 1456, 1379, $1216,754,686 \mathrm{~cm}^{-1}$ (кривая 1 на рис. 2, a). Аналогично для соединения $\mathrm{ZnL5}_{2}(\mathrm{KBr}): 1590,1575,1537,1480$, $1454,1373,1216,755,690 \mathrm{~cm}^{-1}$ (кривая 2 на рис. 2, $a$ ).

Отметим, что полосы валентных колебаний $=\mathrm{CR}-\mathrm{NH}$-фрагмента в ИК-спектрах пленок 

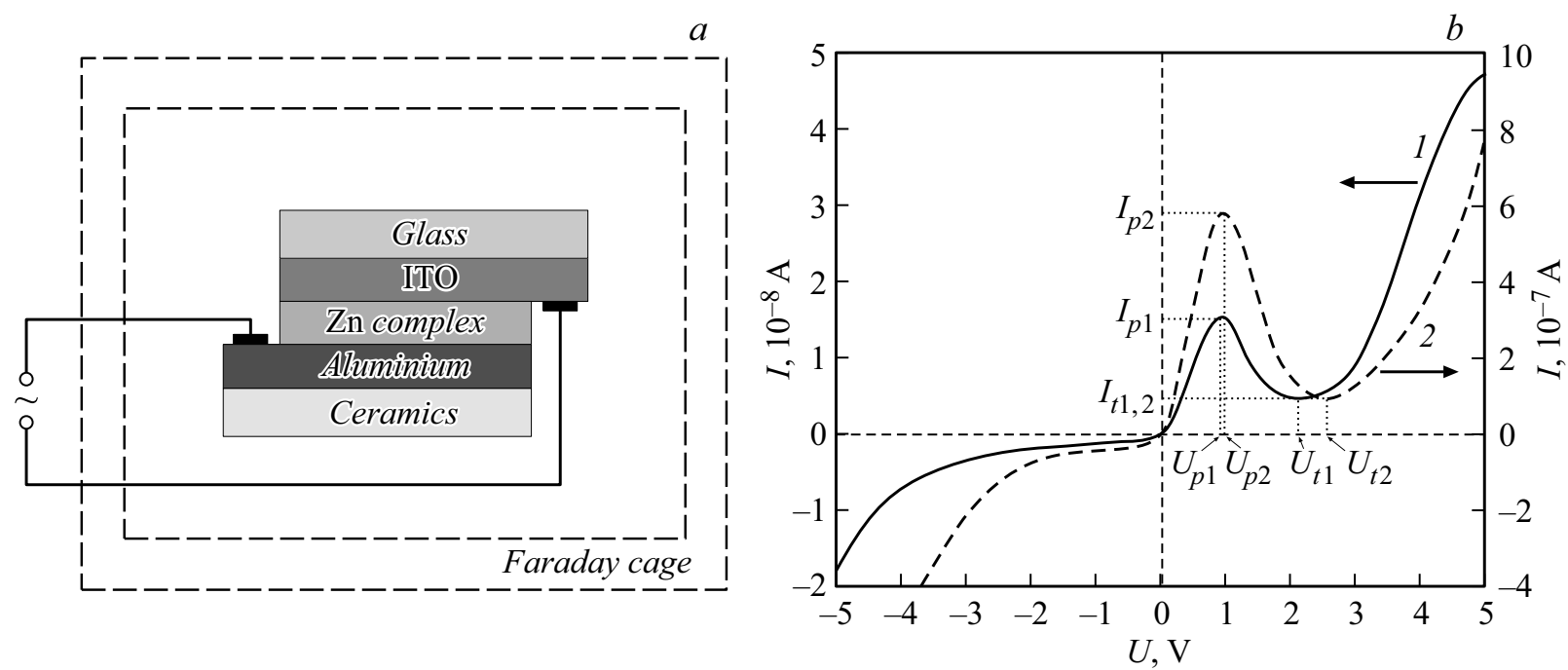

Рис. 3. Сандвич-структура $(a)$ и вольт-амперные характеристики $(b)$ исследованных цинковых комплексов $\mathrm{ZnL} 1_{2}(1)$ и $\mathrm{ZnL} 5_{2}(2)$.

исследуемых комплексов не обнаружены, однако можно выделить сильные и резкие полосы в области $1590 \mathrm{~cm}^{-1}$, которые могут быть отнесены к частоте колебаний азометиновой группы $\mathrm{C}=\mathrm{N}$ координированного лиганда. Новая интенсивная полоса поглощения с максимумом $1379-1373 \mathrm{~cm}^{-1}$, отсутствующая в спектрах свободного лиганда, появляется в спектрах комплексов и отнесена к валентным полосам $\mathrm{C}_{\text {pyrazolone }}-\mathrm{O}$, что подтверждает образование иминольной формы лиганда при координации. Остальные полосы не являются характеристическими и определяются колебаниями функциональных групп.

Анализируя спектры поглощения видимого диапазона цинковых комплексов $\mathrm{ZnL1}_{2}$ и $\mathrm{ZnL}_{2}$, отметим, что максимум поглощения данных материалов находится в диапазоне 360-400 nm (рис. 2, b). Зависимости поглощения от длины волны падающего излучения идентичны, цинковый комплекс $\mathrm{ZnL}_{2}$ имеет чуть более широкий спектр взаимодействия. Учитывая схожесть частотных зависимостей цинковых соединений в оптическом диапазоне и незначительное различие структуры органических комплексов, предположим слабое расхождение параметров оптической ширины запрещенной зоны. Допустив, что основными переходами между валентной зоной и зоной проводимости являются прямые разрешенные переходы, в зависимости коэффициента поглощения от энергии падающего фотона, согласно формуле Тауца, примем степенной показатель $m$ равным 0.5 [11,12]:

$$
\alpha \sim \frac{1}{h v}\left(h v-E_{g}\right)^{m},
$$

где $\alpha-$ коэффициент поглощения, $h v-$ энергия оптического кванта, $E_{g}$ - ширина запрещенной зоны материала. В этом случае оптическая ширина запрещенной зоны цинкового комплекса $\mathrm{ZnL}_{2}$ составила $2.89 \mathrm{eV}$, тогда как для соединения $\mathrm{ZnL}_{2}-2.75 \mathrm{eV}$ (вставка на рис. $2, b)$.
Исследование электрических параметров пленочных цинковых комплексов осуществлялось посредством анализа вольт-амперных характеристик (BAX). Использование в качестве контактной группы тонкопленочного алюминия и оксида индия-олова обусловлено тем, что работа выхода электрона у ITO сравнима с таковой для полимеров, что обеспечивает омический контакт с органическим слоем, тогда как Al образует выпрямляющий барьер из-за более низкой работы выхода [13]. Для увеличения чувствительности и точности измерения, а также уменьшения влияния внешних помех измерения были проведены при температуре $20-25^{\circ} \mathrm{C}$ в экранирующем контейнере - „клетке Фарадея“ (рис. 3, $a$ ).

Общий вид вольт-амперных характеристик для цинковых комплексов $\mathrm{ZnL1}_{2}$ и $\mathrm{ZnL}_{2}$ аналогичен и соответствует $N$-образной BAX (рис. $3, b$ ). Пик для пленки $\mathrm{ZnL}_{2}$ в системе ITO- $\mathrm{ZnL1}_{2}-\mathrm{Al}$ достигается при напряжении $U_{p 1}=0.88 \mathrm{~V}$, при этом ток пика $I_{p 1}=15.1 \mathrm{nA}$. Впадина вольт-амперной характеристики данной структуры соответствует напряжению $U_{t 1}=2.09 \mathrm{~V}$, значение тока впадины $I_{t 1}=4.67 \mathrm{nA}$. Напряжение на второй восходящей части BAX, при котором ток равен пиковому, равно $3.34 \mathrm{~V}$. Обсуждая проводящие свойства цинкового комплекса $\mathrm{ZnL} 5_{2}$ в системе ITO-ZnL5 $-\mathrm{Al}$, отметим, что вольт-амперная характеристика в целом по току на порядок выше, чем для органического соединения $\mathrm{ZnL}_{2}$ $($ рис. $3, b)$. Значения напряжения и тока пика комплекса $\mathrm{ZnL}_{2}$ составляют $U_{p 2}=0.95 \mathrm{~V}$ и $I_{p 2}=5.8 \cdot 10^{-7} \mathrm{~A}$ соответственно, напряжение впадины $U_{t 2}=2.56 \mathrm{~V}$ при токах $I_{t 2}=0.92 \cdot 10^{-7}$ А. Напряжение на восходящей части характеристики равно $4.67 \mathrm{~V}$ при условии равенства тока с параметрами пика.

Механизмы проводимости в органических структуpax достаточно сложны и имеют множество трактовок $[8,14,15]$. Одним из наиболее приемлемых механизмов, на наш взгляд, является прыжковая природа 
переноса носителей заряда по выделенным нитям. Так называемая перколяционная проводимость обусловливается отсутствием монокристалличности, которая присуща классическим полупроводникам. Исходя из этой концепции отрицательную проводимость можно определить наличием встроенных заряженных ловушек, которые при достижении критического напряжения $\left(U_{p}\right)$ блокируют движение (прыжок) носителя. Вторичный рост тока достигается только лишь при напряжениях $\left(U_{t}\right)$, позволяющих увеличить энергию носителя, превосходящую встроенный потенциал [15].

Таким образом, добавление тонкопленочных цинковых комплексов $\mathrm{ZnL1}_{2}$ и $\mathrm{ZnL5}_{2}$ в систему ITO$\mathrm{Zn}$-complex-Al позволяет получить уникальную полупроводниковую структуру. Благодаря простоте конструкции полученного $N$-прибора, малой мощности, а также возможности функционального интегрирования уже сейчас можно говорить о перспективе его использования в различных узлах современной электронной аппаратуры, что требует дополнительных исследований.

\section{Финансирование работы}

Исследование выполнено при финансовой поддержке Российского фонда фундаментальных исследований в рамках научного проекта № 19-32-90038.

\section{Конфликт интересов}

Авторы заявляют, что у них нет конфликта интересов.

\section{Список литературы}

[1] J. Shim, S. Oh, D.-H. Kang, S.-H. Jo, M.H. Ali, W.-Y. Choi, K. Heo, J. Jeon, S. Lee, M. Kim, Y.J. Song, J.-H. Park, Nature Commun., 7, 13413 (2016). DOI: 10.1038/ncomms13413

[2] Y. Liu, F. Li, Z. Chen, T. Guo, C. Wu, T.W. Kim, Vacuum, 130, 109 (2016). DOI: 10.1016/j.vacuum.2016.05.010

[3] V. Malik, S. Maity, R. Chatterjee, Organ. Electron., 56, 5 (2018). DOI: 10.1016/j.orgel.2018.01.027

[4] D. Tonouchi, M.M. Matsushita, K. Awaga, Phys. Rev. B, 96 (4), 045116 (2017). DOI: 10.1103/physrevb.96.045116

[5] Z.B. Yan, J.-M. Liu, Ann. Phys., 358, 206 (2015). DOI: $10.1016 /$ j.aop.2015.03.028

[6] G. Zhou, S. Duan, P. Li, B. Sun, B. Wu, Y. Yao, X. Yang, J. Han, J. Wu, G. Wang, L. Liao, C. Lin, W. Hu, C. Xu, D. Liu, T. Chen, L. Chen, A. Zhou, Q. Song, Adv. Electron. Mater., 4 (4), 1700567 (2018). DOI: 10.1002/aelm.201700567

[7] P. Li, Z. Huang, Z. Fan, Q. Luo, C. Chen, D. Chen, M. Zeng, M. Qin, Z. Zhang, X. Lu, X. Gao, J.-M. Liu, ACS Appl. Mater. Interfaces, 9 (32), 27120 (2017). https://doi.org/10.1021/acsami.7b05634

[8] S. Zhu, B. Sun, S. Ranjan, X. Zhu, G. Zhou, H. Zhao, S. Mao, H. Wang, Y. Zhao, G. Fu, APL Mater., 7 (8), 081117 (2019). DOI: $10.1063 / 1.5100019$
[9] A.N. Gusev, M.A. Kiskin, E.V. Braga, M. Chapran, G. WiosnaSałyga, G.V. Baryshnikov, V.A. Minaeva, B.F. Minaev, K. Ivaniuk, P. Stakhira, H. Agren, W. Linert, J. Phys. Chem. C., 123 (18), 11850 (2019). DOI: 10.1021/acs.jpcc.9b02171

[10] A. Gusev, V. Shul'gin, E. Braga, E. Zamnius, M. Kryukova, W. Linert, Dyes Pigments, 183, 108626 (2020). DOI: $10.1016 /$ j.dyepig.2020.108626

[11] S.T. Tan, B.J. Chen, X.W. Sun, W.J. Fan, H.S. Kwok, X.H. Zhang, S.J. Chua, J. Appl. Phys, 98 (1), 013505 (2005). DOI: $10.1063 / 1.1940137$

[12] А.Н. Гусев, А.С. Мазинов, А.С. Тютюник, И.Ш. Фитаев, В.С. Гурченко, Е.В. Брага, ЖТФ, 91 (1), 89 (2021). DOI: 10.21883/JTF.2021.01.50278.120-20

[13] R.K. Pandey, A.K. Singh, R. Prakash, AIP Adv., 3 (12), 122120 (2013). https://doi.org/10.1063/1.4860952

[14] К.Д. Цэндин, Э.А. Лебедев, А.Б. Шмелькин, ФТТ, 47 (3), 427 (2005). http://journals.ioffe.ru/articles/viewPDF/3752

[15] J.C. Scott, L.D. Bozano, Adv. Mater., 19 (11), 1452 (2007). DOI: $10.1002 /$ adma.200602564 